Article

\title{
Research for the Presence of Unmanned Aerial Vehicle inside Closed Environments with Acoustic Measurements
}

\author{
Giuseppe Ciaburro, Gino Iannace * (1) and Amelia Trematerra \\ Dipartimento di Architettura e Disegno Industriale, Università degli Studi della Campania Luigi Vanvitelli, \\ 81031 Aversa, Italy; giuseppe.ciaburro@unicampania.it (G.C.); amelia.trematerra@unicampania.it (A.T.) \\ * Correspondence: gino.iannace@unicampania.it; Tel.: +39-0815010700
}

Received: 18 April 2020; Accepted: 20 May 2020; Published: 23 May 2020

\begin{abstract}
Small UAVs (unmanned aerial vehicle) can be used in many sectors such as the acquisition of images or the transport of objects. Small UAVs have also been used for terrorist activities or to disturb the flight of airplanes. Due to the small size and the presence of only rotating parts, drones escape traditional controls and therefore represent a danger. This paper reports a methodology for identifying the presence of small UAVs inside a closed environment by measuring the noise emitted during the flight. Acoustic measurements of the noise emitted by a drone inside a large environment $(12.0 \times 30.0 \times 12.0 \mathrm{~m})$ were performed. The noise was measured with a sound level meter placed at different distances $(5,10$, and $15 \mathrm{~m})$, to characterize the noise in the absence of anthropic noise. In this configuration, a typical tonal component of drone noise is highlighted at the frequency of one-third of an octave at $5000 \mathrm{~Hz}$ due to the rotation of the blades. This component is also present $15 \mathrm{~m}$ away from the source point. Subsequent measurements were performed by introducing into the environment, through a loudspeaker, the anthropogenic noise produced by the buzz of people and background music. It is possible to distinguish the typical tonal component of UAV noise at the frequency of $5000 \mathrm{~Hz}$ even when the level of recording of anthropogenic noise emitted by the loudspeaker is at the maximum power tested. It is therefore possible to search for the presence of small UAVs inside a specific closed environment with only acoustic measurements, paying attention to the typical frequency of noise emission equal to $5000 \mathrm{~Hz}$.
\end{abstract}

Keywords: UAV; frequency; acoustic measurements; noise; closed environments

\section{Introduction}

With the acronym UAV, we refer to aircraft without a pilot on board (unmanned aerial vehicle). This category of aircraft determines a drastic reduction in operating costs compared to conventional piloted aircraft. The flight is controlled remotely [1]. Originally drones were used for war purposes with the aim of creating unmanned aircraft to avoid human losses in the event of anti-aircraft defense killing the aircraft $[2,3]$. Technological progress and research in this field have allowed the creation of vehicles capable of realizing the most disparate applications. These results have aroused interest in this technology from the civil sector which today uses UAVs in various fields. Unlike the military sector that uses real planes equipped with destructive weapons, multi-helicopter solutions are widely used in the civil sector [4]. Multi-helicopters are characterized by vehicles with multiple propellers, from three to eight, although the most used choice is the one with four propellers. This is due to an extreme construction simplicity which substantially reduces construction and maintenance costs [5].

Small drones can be used in many sectors such as the acquisition of images, the transport of objects, and being equipped with small speakers they can be used to communicate warnings during 
emergency phases. Although on some rare occasions drones have also been used for terrorist activities (Venezuela 2018 and Saudi Arabia 2019), to disturb the flight of airplanes near airports (London 2019), and for the transport of drugs or the delivery of unwanted objects in prisons; therefore, with UAVs it is possible to perform a series of illegal activities [6]. Even though all the nations of the world have very specific laws prohibiting the overflight of UAVs by creating no fly zones, we are witnessing a worrying increase in reported cases. Due to the small size and the presence of only rotating parts, the UAVs escape the traditional controls; they cannot be seen by infrared systems (thermo cameras) or electronic systems with radio waves and for this they represent a danger for the population. Furthermore, the anti-drone systems so far available are based on the two fundamental principles, intercepting the position and movement of the drone, and annihilating the same by different means [7-17]. The analysis of the airspace to be monitored takes place with four different methods:

- optical, or video cameras capable of distinguishing a drone from a natural bird and operating both day and night thanks to infrared vision;

- radiofrequency, such as scanners that continuously listen to the radio spectrum typically used by drones and their respective remote controls;

- $\quad$ using a radar of limited dimensions expressly dedicated to identifying small flying objects with remote piloting and with a radius of action of a few kilom; and

- using acoustics signatures.

In literature there are several references to studies that have used the noise produced by UAVs for their identification and location [18-36].

This work reports a methodology for the search for the presence of drones inside a closed environment by measuring the noise emitted during the flight. Acoustic measurements of the noise emitted by a drone inside a large environment were performed. The noise was measured with a sound level meter placed at different distances $(5 \mathrm{~m}, 10 \mathrm{~m}$, and $15 \mathrm{~m})$, to characterize the noise in the absence of anthropic noise. In this configuration, a typical tonal component of drone noise was highlighted at the frequency of one-third of an octave at $5000 \mathrm{~Hz}$ due to the rotation of the blades [37]. This component was also present $15 \mathrm{~m}$ away from the source point. Subsequent measurements were performed by introducing into the environment, through a speaker, the anthropogenic noise produced by the buzz of people and background music. This noise was recorded inside an atrium of a shopping center. The level of noise introduced into the environment under test was gradually increased and in the presence of the drone noise, acoustic measurements were carried out at the points previously considered.

\section{Materials and Methods}

For this work the authors adopted a four-propeller radio-controlled drone. The hull of the UAV was made of high-quality acrylonitrile-butadiene-styrene (ABS), while the radio control used a frequency of $2.4 \mathrm{GHz}$. The balance during the flight of the UAV was guaranteed by a 6-axis gyroscope that ensures its stability with a weight of $2.1 \mathrm{~kg}$. Each quadcopter propeller had two blades, while the four propellers rotate alternately: two propellers rotate counterclockwise and the other two clockwise. Figure 1 shows the dimensions of the UAV as well as showing how the four propellers of the UAV are arranged.

The blades are the elements that allow the actual generation of the traction force. The dimensions of the UAVs characterize the type of noise emitted; it is made up of a component due to the airframe and a component due to the aircraft system (the engine noise and propeller noise are negligible) [38-40]. The vortex generated by the propellers and their rotation are the two main components of the noise generated by UAVs. The noise generated by the rotation of the blades at high speed is periodic in nature and is characterized by discrete frequencies obtained by multiplying the number of blades of the propellers by the rotation speed measured in cycles per second. These frequencies represent the fundamental frequencies, to which are then added the higher order harmonics obtained from integer multiples of these frequencies. For the correct identification of the spectral signature it is 
necessary to distinguish the noise produced by the UAV from the environmental noise. We therefore carried out acoustic measurements during the UAV flight in presence of two different anthropogenic noise noises (voices and music) measured inside in hall of a commercial center. To generate the noise produced by the UAV, a tripod was used on which the UAV was anchored. The sound level meter for the acoustic measurements was placed at different distances $(5 \mathrm{~m}, 10 \mathrm{~m}$, and $15 \mathrm{~m})$, while the acoustic measurements were carried out with a sound level meter type Larson Davis type LxT.
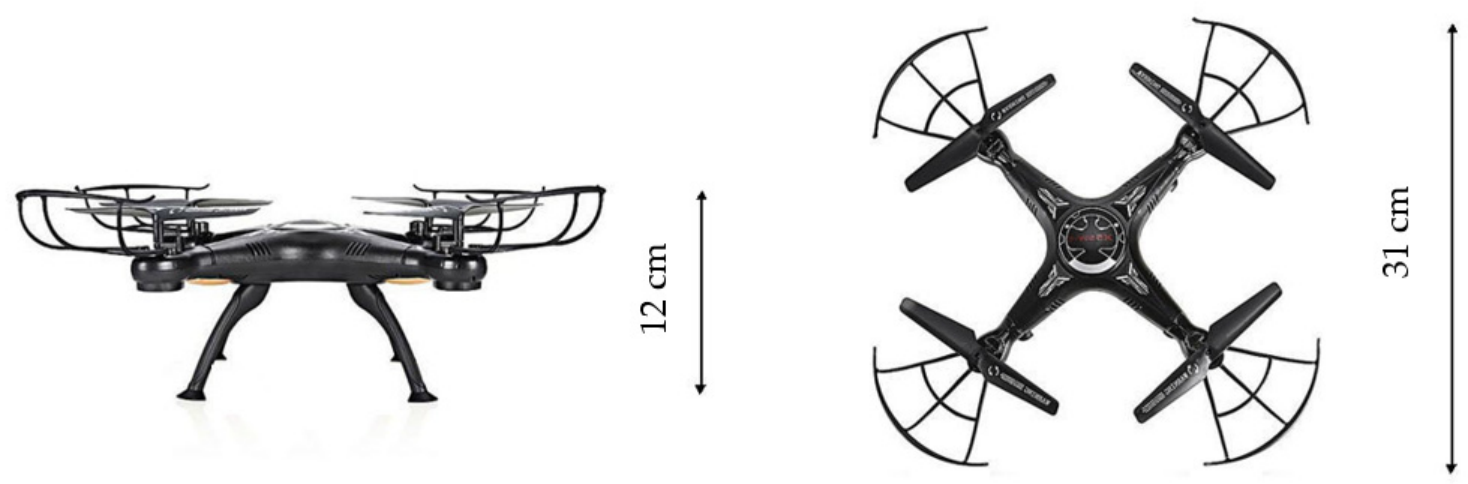

$31 \mathrm{~cm}$

Figure 1. Front and top view and dimensions of the unmanned aerial vehicle (UAV) used.

Anthropogenic noise was recorded via a Zoom digital recorder (Zoom H6 Handy Recorder equipped with a X-Y Microphone) (Zoom North America, New York, USA) to obtain a signal that was subsequently to be reproduced with a loudspeaker in a large environment. This procedure was performed due to the impossibility of carrying out acoustic measurements in a real environment due to the obvious organizational reasons and the difficulties of carrying out measurements in an atrium of a shopping center with the presence of the audience; the atrium volume is equal to $22,610 \mathrm{~m}^{3}$. With the impulse response method and in accordance with ISO 3382 [41,42], the environment was characterized from an acoustic point of view with the following reverberation time values $T_{30}$, s. Table 1 shows the reverberation time in octave band measured in the atrium of the shopping center [43].

Table 1. Reverberation time in octave band measured in the atrium of the shopping center.

\begin{tabular}{ccccccc}
\hline Frequency, $\mathbf{H z}$ & $\mathbf{1 2 5}$ & $\mathbf{2 5 0}$ & $\mathbf{5 0 0}$ & $\mathbf{1 0 0 0}$ & $\mathbf{2 0 0 0}$ & $\mathbf{4 0 0 0}$ \\
\hline $\mathrm{T}_{30}, \mathrm{~s}$ & 1.92 & 2.07 & 2.19 & 2.23 & 2.13 & 1.72 \\
\hline
\end{tabular}

The environment under test is an industrial warehouse that houses a measurement laboratory with the following dimensions, width $12 \mathrm{~m}$, length $30 \mathrm{~m}$, and height $12 \mathrm{~m}$ (volume $=4320 \mathrm{~m}^{3}$ ). The walls are covered with smooth plaster while the floor is concrete with glass surfaces. Inside there are equipment and machinery typical of a measurement laboratory. Table 2 shows the reverberation time in octave band measured in the atrium of the shopping center.

Table 2. Reverberation time in octave band measured in the environment test.

\begin{tabular}{ccccccc}
\hline Frequency, $\mathbf{H z}$ & $\mathbf{1 2 5}$ & $\mathbf{2 5 0}$ & $\mathbf{5 0 0}$ & $\mathbf{1 0 0 0}$ & $\mathbf{2 0 0 0}$ & $\mathbf{4 0 0 0}$ \\
\hline $\mathrm{T}_{30}, \mathrm{~s}$ & 2.5 & 2.8 & 3.2 & 3.3 & 2.9 & 2.4 \\
\hline
\end{tabular}




\subsection{UAV Acoustic Characterization inside the Anechoic Chamber}

A measurement was first performed in the anechoic chamber to characterize the sound emission of the UAV [44-46]. The anechoic chamber with the following dimensions $(4.40 \mathrm{~m} \times 4.40 \mathrm{~m} \times 4.50 \mathrm{~m})$, allowed us to perform noise measurements in the absence of background noise and in a free field. In this way it was possible to estimate the emission spectrum of the UAV in the absence of unwanted sound reflections due to the surfaces of the environment, and to evaluate the tonal components of the UAV. Figure 2 shows the trend of the sound spectrum in a frequency of one-third octave bands both for the minimum values and for the average values measured. The UAV considered has a tonal component at a frequency of $5000 \mathrm{~Hz}$. From these observations, to verify if there is a UAV active in the indoor environment, we could perform a measurement of noise emissions with a sound level meter and check for the presence of a tonal component at $5000 \mathrm{~Hz}$.
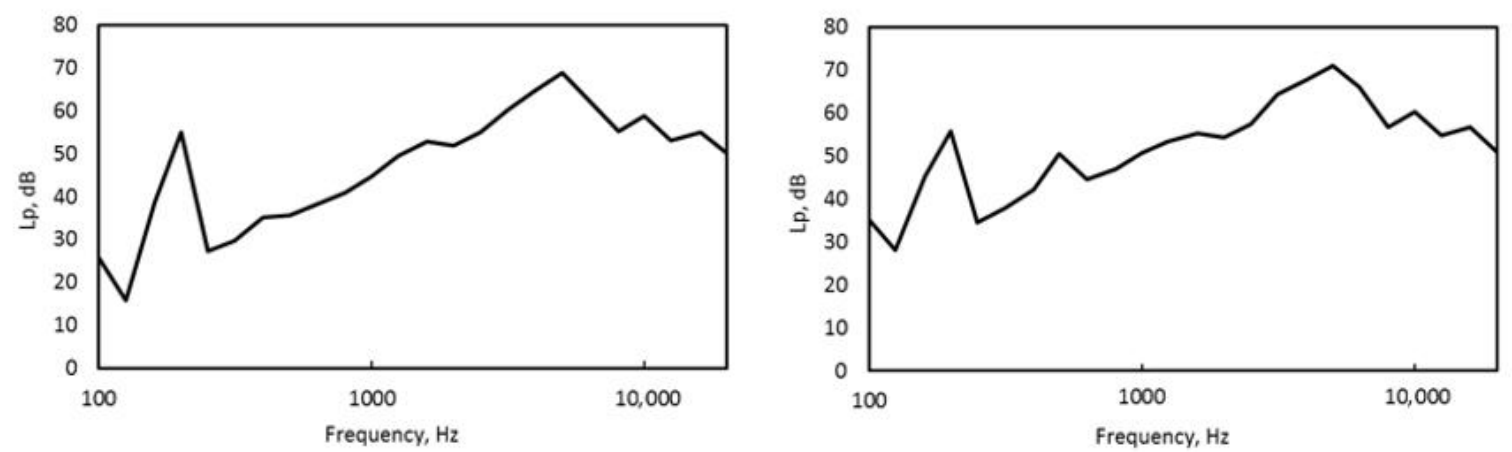

Figure 2. Values of the minimum (at the left) and average (at the right) spectrum emitted in the anechoic chamber by the operation of a UAV. It is possible to note the presence of the $5000 \mathrm{~Hz}$ tonal component.

\subsection{Acoustic Measurements in Real Environment in the Absence Of Anthropic Noise}

The UAV was placed inside an industrial warehouse that houses a measurement laboratory. The shed is located in an area where there is no vehicular traffic or other forms of noise pollution. The measuring sound level meter was placed at three different distances $(5 \mathrm{~m}, 10 \mathrm{~m}$, and $15 \mathrm{~m}$ from the position where the UAV was placed). Figure 3 shows the plan of the position of the UAV on the stand, during the acoustic measurement phases, with respect to the positions of the sound level $\mathrm{m}$. The first series of measurements were performed in the absence of any form of noise in the environment.

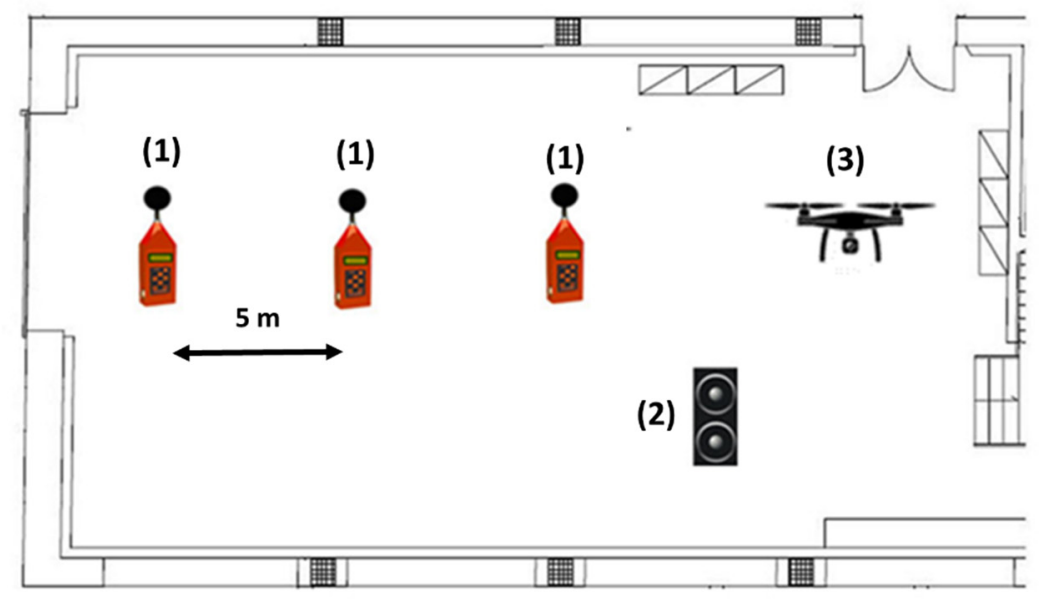

Figure 3. Plan of the internal simulation environment. The positions of the elements used in the simulation scenarios are clearly indicated: sound level meter (1), loudspeaker (2), and UAV (3). 
In the absence of anthropic noise configuration, Figure 4 shows the values of the minimum and average spectrum emitted by the UAV in the environment under test in the frequency domain of a one-third octave band. The receiver-noise source distances are respectively (A equals $5 \mathrm{~m}$ ), (B equals $10 \mathrm{~m}$ ), and (C equals $15 \mathrm{~m})$. It is possible to note the tonal component presence at the frequency of $5000 \mathrm{~Hz}$.
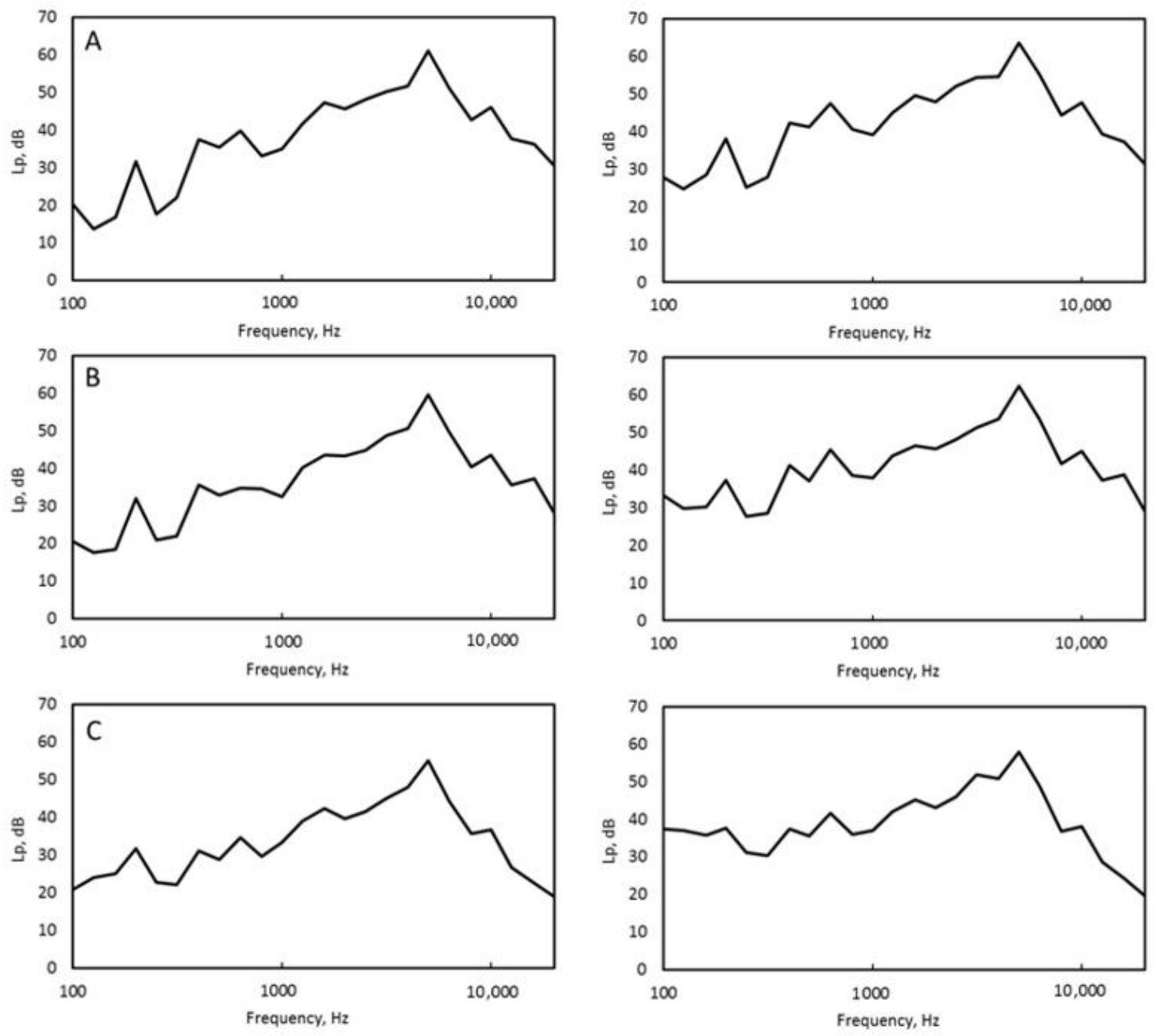

Figure 4. Values of the minimum (at the left) and average (at the right) spectrum emitted in the position of the UAV in the environment under test, in absence of noise. The receiver-source distances are respectively: ((A) equals $5 \mathrm{~m}$, (B) equals $10 \mathrm{~m}$, and (C) equals $15 \mathrm{~m})$.

\subsection{Acoustic Measurements in the Environment with Anthropic Noise (Voice)}

The second series of the acoustic measurements were carried out in the presence of voice noise, previously recorded inside the atrium of a shopping center, generated by a loudspeaker. The recording of the noise emitted by the voice was performed in the atrium of a very popular shopping center on a weekend evening. This allowed the recording of the typical voices of people when they are present in a large environment. The purpose of the recording was to obtain a realistic audio signal that could be compared with the noise emission of the UAV. For this purpose, the understanding of the voice was not necessary, but only the typical spectrum of the sound emissions of people on the move. Through a loudspeaker the noise was introduced into the environment under test. The LAeq level in the environment was equal to $61 \mathrm{dBA}$ (measured for five minutes), corresponding to the sound level inside the atrium of the shopping center. Furthermore, since the environment under test was a large empty volume, the sound level was on average widespread. Figure 5 shows the values of 
the minimum and average spectrum measured within the environment in this configuration, in the frequency domain of one-third octave bands. The receiver-noise source distances are respectively: (A equals $5 \mathrm{~m}$ ), (B equals $10 \mathrm{~m}$ ), and (C equals $15 \mathrm{~m}$ ). Furthermore, in this configuration it is possible to notice the presence of the tonal component at the frequency of $5000 \mathrm{~Hz}$. In this condition the Figure $5 \mathrm{C}$ (sound source-receiver distance equal to $15 \mathrm{~m}$ ), due to the distance the emission level of the UAV, begins to decrease to approach the emission level of the voice. Although the tonal component at the frequency of $5000 \mathrm{~Hz}$, typical of the emission of the $\mathrm{UAV}$, always remains detached from other vocal sound components.
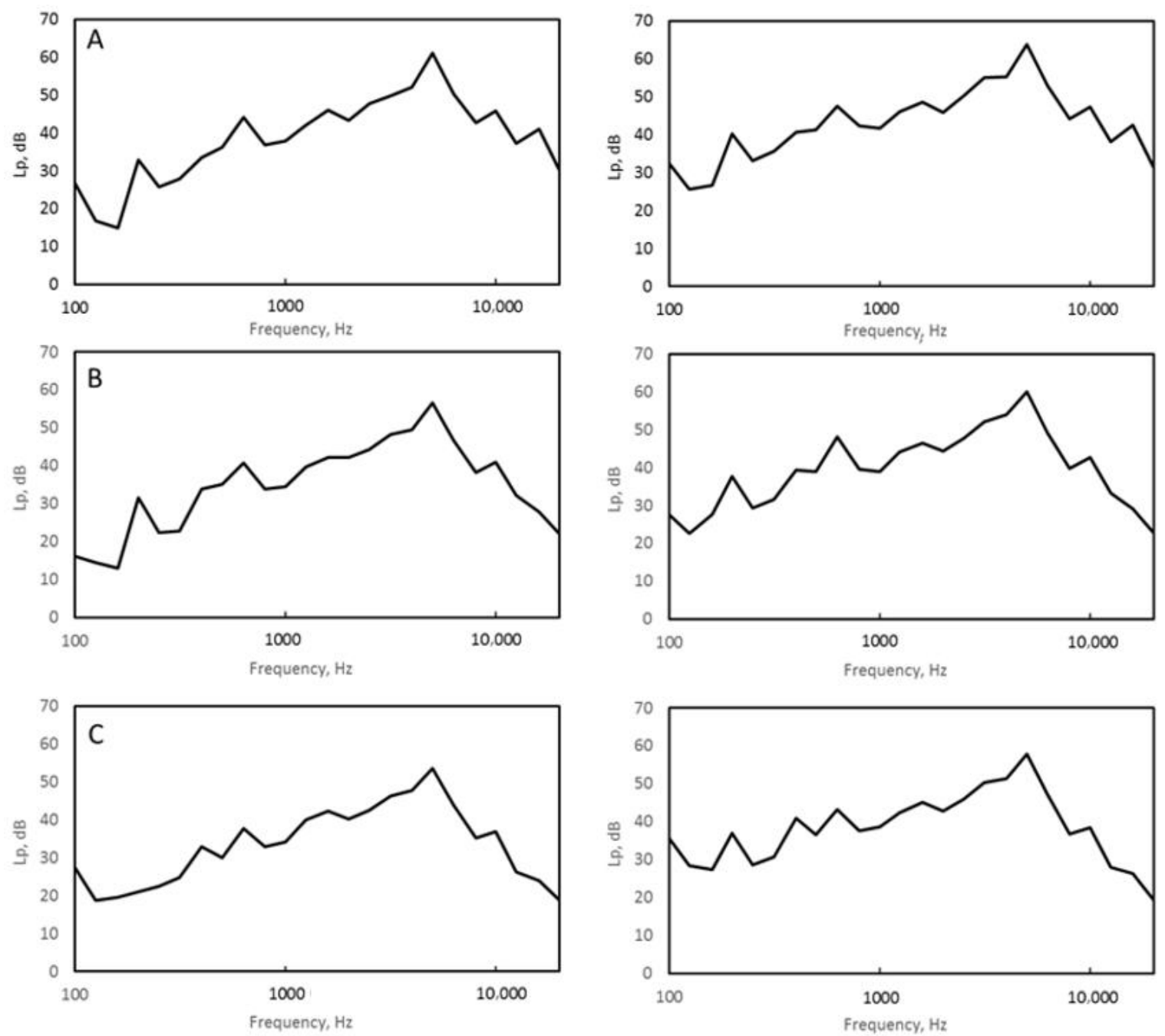

Figure 5. Values of the minimum (at the left) and average (at the right) spectrum emitted in the position of the UAV in the environment under test, with anthropic noise (voice). The receiver-source distances are respectively: ((A) equals $5 \mathrm{~m}$, (B) equals $10 \mathrm{~m}$, and (C) equals $15 \mathrm{~m}$ ).

\subsection{Acoustic Measurements in the Environment with Anthropic Noise (Music)}

The third series of measurements were performed by generating the music previously recorded inside the atrium of the shopping center. The recorded music was emitted from the speakers for advertising purposes. The purpose of recording the musical signal was to obtain a realistic audio signal that could be compared with the noise emission of the UAV. Through a loudspeaker the noise was introduced into the environment under test. The LAeq noise level inside the environment was equal to $71 \mathrm{dBA}$ (measured for five mins), corresponding to the sound level in real conditions inside the atrium of the shopping center. The sound level emitted within the environment under test was 
on average widespread. Figure 6 shows the values of the minimum and average emitted spectrum measured within the environment in this configuration. Moreover, in this configuration it was possible to notice the presence of the tonal component at the frequency of $5000 \mathrm{~Hz}$. The receiver-noise source distances are respectively: (A equals $5 \mathrm{~m}$ ), (B equals $10 \mathrm{~m}$ ), and (C equals $15 \mathrm{~m}$ ). In the conditions analyzed in Figure 6, the issue of music emission is always well separated from the tonal component frequency of $5000 \mathrm{~Hz}$, typical of the UAV emission. It remains always detached from the other sonic components of the music.
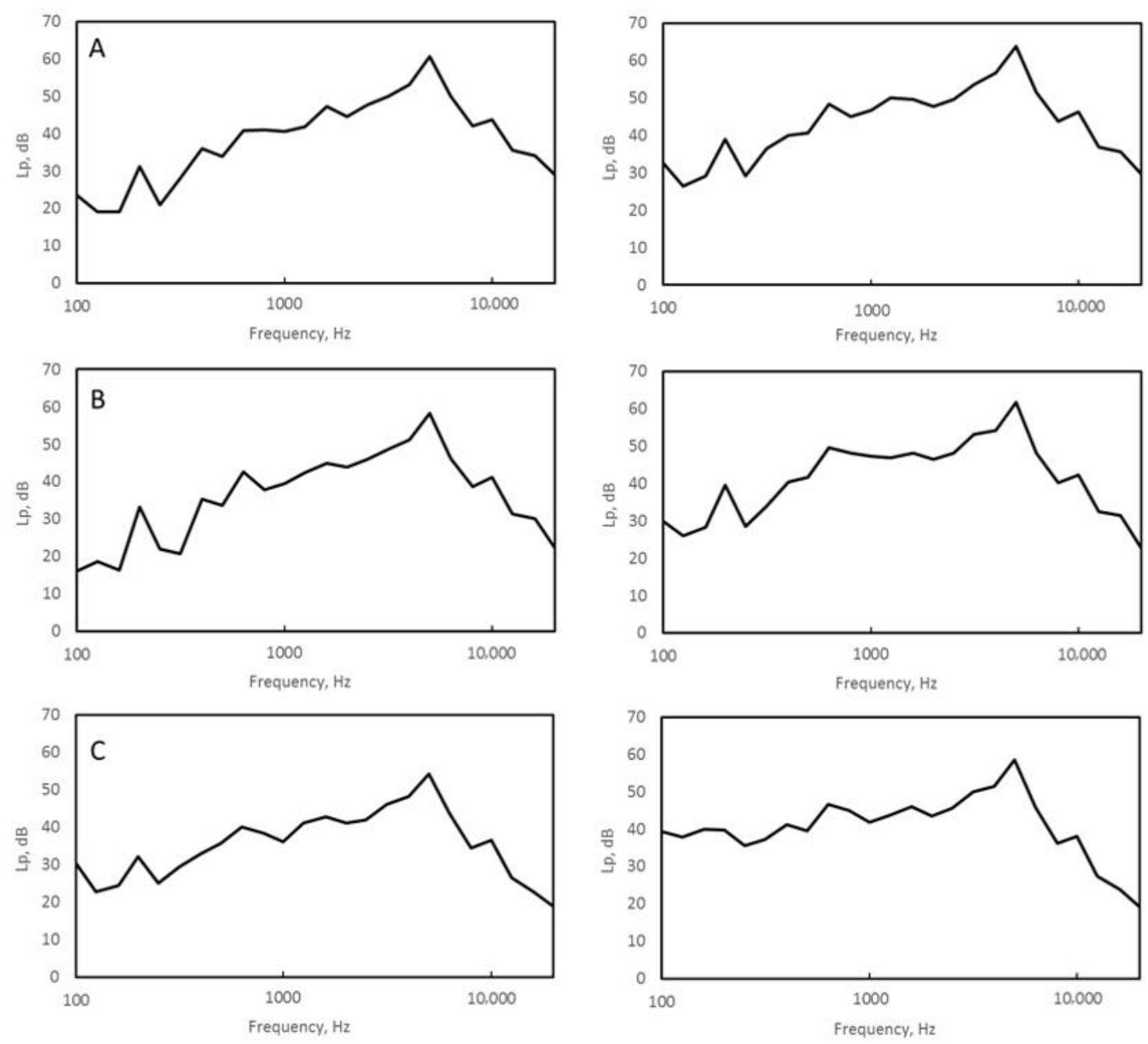

Figure 6. Values of the minimum (at the left) and average (at the right) spectrum emitted in the position of the UAV in the environment under test, with anthropic noise (music). The receiver-source distances are respectively: ((A) equals $5 \mathrm{~m},(\mathbf{B})$ equals $10 \mathrm{~m}$, and $(\mathbf{C})$ equals $15 \mathrm{~m})$.

\section{Discussion}

The purpose of this work was the search for a UAV inside a closed environment in the presence of an anthropogenic noise (voice and music) with acoustic measurements carried out with a sound level meter. First, a preliminary measurements session in anechoic chamber was executed, then acoustic measurements were performed in an industrial warehouse and using a loudspeaker, and then the vocal and subsequently the music that had been recorded inside the hall of an atrium of a shopping center was spread. The UAV was placed on a tripod and during operation the sound emission values were measured with a sound level meter placed at fixed points $(5 \mathrm{~m}, 10 \mathrm{~m}$, and $15 \mathrm{~m})$. The results of the acoustic measurements were reported in a frequency in one-third octave bands. The measurements 
were carried out in the presence of noise emitted from the audio registration of the audience who frequent the atrium of a shopping mall, or from music inside the atrium. The sound levels due to the emission of vocals or music within the environment under test were on average widespread in the sense that they did not change when the measurement position changes. This was due to the large size of the environment and the consequent values of the time reverberation measured $\left(T_{30}=3.3 \mathrm{~s}\right.$ at the frequency of $1000 \mathrm{~Hz}$ ). These acoustic measurements highlight the presence of a tonal component at the frequency of $5000 \mathrm{~Hz}$, which represents the typical sound emission of the UAV during the flying operating phase. The identification of this frequency is the sign of the presence of a UAV in the environment. Depending on the conditions of acoustic measurements performed with the voice and with the music, it should be noted that the spectra in the two conditions are different from each other. The spectrum in the condition of the emission of the voice at the frequency of $500 \mathrm{~Hz}$ reached a maximum and then slightly decreased, while the emission spectrum of the music was flat in the frequency range considered.

\section{Conclusions}

The purpose of this paper was the search for a UAV in the studied environment in the presence of anthropogenic noise (voice and music) with acoustic measurements carried out with a sound level meter. The search for the presence of a UAV was somewhat complex and not simple for its small size. Given the difficulty of making measurements in a real environment for organizational security needs in crowded places, the acoustic measurements were simulated in an industrial environment. The paper focused on the noise emissions of the UAV during the operating phases inside a large environment simulating flight activities inside the atrium of a shopping center. The analysis of the acoustic measurements showed a tonal component at the one-third octave at the frequency of $5000 \mathrm{~Hz}$. This tonal component was present both when the voice was present in the environment under test, and when the music was present. Therefore, simple acoustic measurements and a frequency analysis can confirm the presence of UAVs in the studied environment.

Author Contributions: Conceptualization, G.I. and G.C.; methodology, G.C.; investigation, G.C.; measurements G.I. and G.C.; software G.C.; post processing data, G.I. and G.C.; data curation, A.T.; writing-original draft preparation, A.T.; writing-review and editing, A.T.; visualization, G.C. and A.T.; supervision, G.I.; references study, A.T.; and setup measurements, G.I. and G.C. All authors have read and agreed to the published version of the manuscript.

Funding: This research received no external funding.

Conflicts of Interest: The authors declare no conflict of interest.

\section{References}

1. Valavanis, K.P.; Vachtsevanos, G.J. (Eds.) Handbook of Unmanned Aerial Vehicles; Springer: Dordrecht, The Netherlands, 2015; Volume 1.

2. Lyon, D.H. A military perspective on small unmanned aerial vehicles. IEEE Instrum. Meas. Mag. 2004, 7, 27-31. [CrossRef]

3. Pardesi, M.S. Unmanned aerial vehicles/unmanned combat aerial vehicles: Likely missions and challenges for the policy-relevant future. Air Space Power J. 2005, 19, 45.

4. Nonami, K.; Kendoul, F.; Suzuki, S.; Wang, W.; Nakazawa, D. Autonomous Flying Robots: Unmanned Aerial Vehicles and Micro Aerial Vehicles; Springer Science \& Business Media: New York, NY, USA, 2010.

5. Newcome, L.R. Unmanned Aviation: A Brief History of Unmanned Aerial Vehicles; American Institute of Aeronautics and Astronautics: Washington, DC, USA, 2004.

6. Zhang, Z.; Cao, Y.; Ding, M.; Zhuang, L.; Yao, W. An intruder detection algorithm for vision based sense and avoid system. In Proceedings of the International Conference on Unmanned Aircraft Systems (ICUAS), Arlington, VA, USA, 7-10 June 2016; pp. 550-556. 
7. Ganti, S.R.; Kim, Y. Implementation of detection and tracking mechanism for small UAS. In Proceedings of the International Conference on Unmanned Aircraft Systems (ICUAS), Arlington, VA, USA, 7-10 June 2016; pp. 1254-1260.

8. Christnacher, F.; Hengy, S.; Laurenzis, M.; Matwyschuk, A.; Naz, P.; Schertzer, S.; Schmitt, G. Optical and acoustical UAV detection. In Electro-Optical Remote Sensing $X$; International Society for Optics and Photonics: San Diego, CA, USA, 2016; Volume 9988, p. 99880B.

9. Du, L.; Gao, C.; Feng, Q.; Wang, C.; Liu, J. Small UAV Detection in Videos from a Single Moving Camera. In CCF Chinese Conference on Computer Vision; Springer: Singapore, 2017; pp. 187-197.

10. Prates, P.A.; Mendonça, R.; Lourenço, A.; Marques, F.; Matos-Carvalho, J.P.; Barata, J. Vision-based UAV detection and tracking using motion signatures. In Proceedings of the IEEE Industrial Cyber-Physical Systems (ICPS), St. Petersburg, Russia, 15-18 May 2018; pp. 482-487.

11. Martinez, P.; Barczyk, M. Implementation and optimization of the cascade classifier algorithm for UAV detection and tracking. J. Unmanned Veh. Syst. 2019, 7, 296-311. [CrossRef]

12. Nguyen, P.; Ravindranatha, M.; Nguyen, A.; Han, R.; Vu, T. Investigating cost-effective rf-based detection of drones. In Proceedings of the 2nd Workshop on Micro Aerial Vehicle Networks, Systems, and Applications for Civilian Use, 2016; ACM: New York, NY, USA, 2016; pp. 17-22. Available online: https://dl.acm.org/doi/ 10.1145/2935620.2935632 (accessed on 22 May 2020).

13. Haluza, M.; Čechák, J. Analysis and decoding of radio signals for remote control of drones. In Proceedings of the New Trends in Signal Processing (NTSP), Demanovska Dolina, Slovakia, 12-14 October 2016; pp. 1-5.

14. Ezuma, M.; Erden, F.; Anjinappa, C.K.; Ozdemir, O.; Guvenc, I. Detection and Classification of UAVs Using RF Fingerprints in the Presence of Wi-Fi and Bluetooth Interference. IEEE Open J. Commun. Soc. 2019, 1, 60-76. [CrossRef]

15. Samaras, S.; Magoulianitis, V.; Dimou, A.; Zarpalas, D.; Daras, P. UAV Classification with Deep Learning Using Surveillance Radar Data. In International Conference on Computer Vision Systems; Springer: Cham, Switzerland, 2019; pp. 744-753.

16. Ostovar, A.; Talbot, B.; Puliti, S.; Astrup, R.; Ringdahl, O. Detection and classification of Root and Butt-Rot (RBR) in stumps of Norway Spruce using RGB images and machine learning. Sensors 2019, 19, 1579. [CrossRef] [PubMed]

17. Shastry, A.K.; Sinha, H.; Kothari, M. Autonomous Detection and Tracking of a High-Speed Ground Vehicle using a Quadrotor UAV. In Proceedings of the AIAA Scitech 2019 Forum, San Diego, CA, USA, 7-11 January 2019; p. 1188.

18. Fioranelli, F.; Ritchie, M.; Griffiths, H.; Borrion, H. Classification of loaded/unloaded micro-drones using multistatic radar. Electron. Lett. 2015, 51, 1813-1815. [CrossRef]

19. Drozdowicz, J.; Wielgo, M.; Samczynski, P.; Kulpa, K.; Krzonkalla, J.; Mordzonek, M.; Bryl, M.; Jakielaszek, Z. $35 \mathrm{GHz}$ FMCW drone detection system. In Proceedings of the 17th International Radar Symposium (IRS), Krakow, Poland, 10-12 May 2016; pp. 1-4.

20. Klare, J.; Biallawons, O.; Cerutti-Maori, D. Detection of UAVs using the MIMO radar MIRA-CLE Ka. In Proceedings of the 11th European Conference on Synthetic Aperture Radar (EUSAR 2016), Hamburg, Germany, 6-9 June 2016; pp. 1-4.

21. Moses, A.; Rutherford, M.J.; Valavanis, K.P. Radar-based detection and identification for miniature air vehicles. In Proceedings of the IEEE International Conference on Control Applications (CCA), Denver, CO, USA, 28-30 September 2011; pp. 933-940.

22. Mohajerin, N.; Histon, J.; Dizaji, R.; Waslander, S.L. Feature extraction and radar track classification for detecting UAVs in civillian airspace. In Proceedings of the 2014 IEEE Radar Conference, Cincinnati, $\mathrm{OH}$, USA, 19-23 May 2014; pp. 0674-0679.

23. Sadasivan, S.; Gurubasavaraj, M.; Sekar, S.R. Acoustic signature of an unmanned air vehicle exploitation for aircraft localisation and parameter estimation. Def. Sci. J. 2001, 51, 279-284. [CrossRef]

24. Harvey, B.; O'Young, S. Detection of continuous ground-based acoustic sources via unmanned aerial vehicles. J. Unmanned Veh. Syst. 2015, 4, 83-95. [CrossRef]

25. Hammer, M.; Borgmann, B.; Hebel, M.; Arens, M. UAV detection, tracking, and classification by sensor fusion of a $360^{\circ}$ lidar system and an alignable classification sensor. In Laser Radar Technology and Applications XXIV; International Society for Optics and Photonics: San Diego, CA, USA, 2019; Volume 11005, p. 110050E. 
26. Case, E.E.; Zelnio, A.M.; Rigling, B.D. Low-cost acoustic array for small UAV detection and tracking. In Proceedings of the IEEE National Aerospace and Electronics Conference, Dayton, OH, USA, 23-26 July 2018; pp. 110-113.

27. Pham, T.; Srour, N. TTCP AG-6: Acoustic detection and tracking of UAVs. In Unattended/Unmanned Ground, Ocean, and Air Sensor Technologies and Applications VI; International Society for Optics and Photonics: San Diego, CA, USA, 2004; Volume 5417, pp. 24-30.

28. Ramamonjy, A.; Bavu, E.; Garcia, A.; Hengy, S. A distributed network of compact microphone arrays for drone detection and tracking. J. Acoust. Soc. Am. 2017, 141, 3651. [CrossRef]

29. Culver, R.L. Frequency-dependent beam pattern of acoustic arrays for unmanned aerial vehicle tracking. J. Acoust. Soc. Am. 2016, 139, 2020. [CrossRef]

30. Sedunov, A.; Sutin, A.; Salloum, H. Application of cross-correlation methods for passive acoustic unmannded aierial vehicle detection and tracking. J. Acoust. Soc. Am. 2016, 140, 3119. [CrossRef]

31. Goldman, G.H. Detection results for a class 1 unmanned aerial vehicle measured with a small microphone array. J. Acoust. Soc. Am. 2015, 138, 1755. [CrossRef]

32. Goldman, G.H.; Culver, R.L. Tracking unmanned aerial vehicles using a tetrahedral microphone array. J. Acoust. Soc. Am. 2014, 136, 2213. [CrossRef]

33. Grasing, D. An analysis of methods for the acoustic localization of unattended aerial vehicles. J. Acoust. Soc. Am. 2016, 140, 3404. [CrossRef]

34. Bernardini, A.; Mangiatordi, F.; Pallotti, E.; Capodiferro, L. Drone detection by acoustic signature identification. Electron. Imaging 2017, 2017, 60-64. [CrossRef]

35. Matson, E.; Yang, B.; Smith, A.; Dietz, E.; Gallagher, J. UAV detection system with multiple acoustic nodes using machine learning models. In Proceedings of the 2019 Third IEEE International Conference on Robotic Computing (IRC), Naples, Italy, 25-27 February 2019; pp. 493-498.

36. Kloet, N.; Watkin, S.; Clothier, R. Acoustic signature measurement of small multi-rotor unmanned aircraft systems. Int. J. Micro Air Veh. 2017, 9, 3-14. [CrossRef]

37. Iannace, G.; Ciaburro, G.; Trematerra, A. Fault diagnosis for uav blades using artificial neural network. Robotics 2019, 8, 59. [CrossRef]

38. Kurtz, D.W.; Marte, J.E. A Review of Aerodynamic Noise from Propellers, Rotors, and Lift Fans; NASA: Greenbelt, MA, USA, 1970.

39. Jokisch, O.; Siegert, I.; Maruschke, M.; Strutz, T.; Ronzhin, A. Don't Talk to Noisy Drones-Acoustic Interaction with Unmanned Aerial Vehicles. In International Conference on Speech and Computer; Springer: Cham, Switzerland, 2019; pp. 180-190.

40. Jokisch, O.; Fischer, D. Drone sounds and environmental signals-A first review. In Proceedings of the ESSV Conference (Studientexte zur Sprachkommunikation), Dresden, Germany, 6-8 March 2019; Peter Birkholz and Simon Stone: Dresden, Germany, 2019; Volume 93, pp. 212-220. Available online: http://www.essv.de/paper.php?id=84 (accessed on 21 May 2020).

41. ISO 3382-1: 2012. Acoustics—Measurement of Room Acoustic Param-Part 1: Performance Spaces; International Organization for Standardization: Geneva, Switzerland, 2012.

42. ISO 3382-2: 2012. Acoustics-Measurement of Room Acoustic Param-Part 2: Reverberation Time in Ordinary Rooms; International Organization for Standardization: Geneva, Switzerland, 2012.

43. Iannace, G.; Ianniello, C.; Ianniello, E. Music in an atrium of a shopping center. Acoust. Aust. 2015, 43, 191-198. [CrossRef]

44. Iannace, G.; Ciaburro, G.; Trematerra, A. Heating, ventilation, and air conditioning (hvac) noise detection in open-plan offices using recursive partitioning. Buildings 2018, 8, 169. [CrossRef]

45. Papa, U.; Iannace, G.; Del Core, G.; Giordano, G. Determination of sound power levels of a small UAS during flight operations. In Proceedings of the INTER-NOISE 2016 - 45th International Congress and Exposition on Noise Control Engineering: Towards a Quieter Future, Hamburg, Germany, 21-24 August 2016; pp. $216-226$.

46. Papa, U.; Iannace, G.; Del Core, G.; Giordano, G. Sound power level and sound pressure level characterization of a small unmanned aircraft system during flight operations. Noise Vib. Worldw. 2017, 48, 67-74. [CrossRef] 